\title{
Contribution in isolation and identification of some pathogenic fungi from wheat seeds, and evaluation of antagonistic capability of Trichoderma harzianum against those isolated fungi in vitro.
}

\author{
Hamitou Mokhtar ${ }^{1}$ and Aid Dehimat ${ }^{2}$ \\ ${ }^{1}$ Department of Nature and Life Sciences, faculty of exact sciences and nature and life \\ Sciences, University of Larbi Ben Mehidi, Oum-elbouaghi, Algeria. \\ 2 Department of Biochemistry and Microbiology, Faculty of nature and life Sciences, \\ University of Mentouri, Constantine, Algeria.
}

\begin{abstract}
The aim of this study was to isolate and to identify the pathogenic fungi accompanying interior in hard wheat seeds, and to evaluate the antagonism capability in vitro of (Trichoderma harzianum) against those pathogenic isolated fungi. Three samples of local hard wheat seeds (Triticum durum Desf) were brought from Oum-elbouaghi (Algeria) silos yields, follower for varieties: Vitron, Waha, and Cirta. ).They were stored for one year. The results of isolation on potato-dextroseagar (PDA) medium and after identification of fungal accompanying interior in the seeds clarified about (83) fungus isolates following for species next : Fusarium acuminatum (1 isolate) in a ratio of $(1.2 \%)$, and Alternaria(82 isolates) with a ratio of $(98.795 \%)$.The Alternaria isolates apportioned among two species: Alternaria alternata with 39 isolates(12 isolates for: Alternaria alternata1 and 27 isolates for : Alternaria alternata2) and Alternaria infectoria with 43 isolates).And, besides it was clearly seen that the Cirta variety was a lowest infected with fungi(19 isolates) in ratio of $(22.89 \%)$, and both varieties Waha and Vitron with(32 isolates)for each one in a ration equal $(38.554 \%)$. The results of the antagonistic capability in vitro of (Trichoderma harzianum) against isolated fungi, showed that: 1- The direct confrontation in vitro of Trichoderma harzianum against the different fungus isolates on PDA medium, showed that: aIn the fourth day of the experiment, Trichoderma harzianum inhibited the mycelia growth of different pathogenic fungi in dual cultures, with different ratios, it was equal to: $6.66 \%$ for Fusarium acuminatum, and $23 \%, 26.66 \%$ and $40 \%$ for Alternaria alternata1, Alternaria alternata2, and Alternaria infectoria, respectively. b-The microscopic observations of the different interactions hyphal between Trichoderma harzianum and different fungus isolates, showed that the antagonistic fungus affected on Alternaria species with the decomposition phenomenon (Lyses), where it analyzed the mycelia and spores of Alternaria altrenata2 and Alternaria infectoria, while it analyzed the mycelia of Alternaria alternata1, compared with control. 2- The remote confrontation in vitro of Trichoderma harzianum against the different fungus isolates on PDA medium showed that : a- The volatile metabolic substances of Trichoderma harzianum affected the growth of the different pathogenic fungi, with different ratios over the seven days of treatment, compared with control.b- The microscopic observations Noted that the volatile metabolic substances of Trichoderma harzianum affected some isolated fungi with mycelia analysis prevent the spore's formation of the Alternaria alternata2, while stopped the spore formation of Fusarium acuminatum, compared with control.
\end{abstract}

Key words: wheat seeds, antagonistic, Fusarium acuminatum, Trichoderma harzianum, Alternaria.

\section{INTRODUCTION}

Wheat seeds are a favorable medium for the pathogenic mycoflore and carrying them, those fungi cause a decrease in both seed vitality, and nutritional value, moreover the excretion of mycotoxins (Moreno and al., 1986). Alternaria genus contains a great number of species plus of sixty, parasites or saprophytes, there effect announced on seeds; Alternaria parasites are the origin of the germination lacks, sowing dissolution and there are significant inoculum sources of the adult plants. (Rémi, 1997). Different taxa in the species-group of Alternaria infectoria (teleomorph Lewia spp.) are often isolated 
from various cereals including barley, maize and wheat grain, ornamental plants and skin lesions from animals and humans.(Andersen and al.,2009). Alternaria alternata present on all species of seeds, it met on the leaves, the fruits or seeds of many plants of various parasites or at the end of the vegetation (Rémi, 1997). In pathogenicity study of five Fusarium spp frequently isolated from wheat and barley roots in the southern Idaho during growth -chamber experiments and field studies showed that the presence of Fusarium culmorum from infected root tissue, followed by F.acuminatum and F. reticulatum, however F.semitectum, followed by F.acuminatum and F.equiseti had the greatest impact on total root length (Carl and al., 2005). The addition of chemical fungicides may reduce or eliminate fungal growth on the seeds, but they can decrease the seed vitality at the same time. (Moreno et al., 1986). chemical pesticides cause a significant damage to the public health, environment and groundwater pollution; also, it is uneconomical, so that, recently the scientists use the biological control. In bibliographical study of more than 200 research was found that the Trichoderma $s p$ plays an important role in biological control, and it represents $60 \%$ of all other biofungicides include bacteria, nematode and virus, it used as a pesticide, and herbicide; also found that the use of this fungus was improved the plant growth (Mausam and al., 2007). A treatment of Crossandra infundibuliformis var.Danica with Trichoderma viride and T.harzianum decreased the wilt diseases which caused by Fusarium oxysporium, and increased the plant growth, both in the field trials and in laboratory alike; that study strongly suggests that the Trichoderma isolates, especially, T.viride can be exploited for the biological control of wilt disease at field level (Jegathambigai and al., 2009). Trichoderma viride and T.harzianum were used in the control against the associated fungi with seeds, including Aspergillus flavus and Fusarium moniliforme; also they were used as anti-fungal against Lasiodiplodia theobroma, Diplodia natalensis, Botryodiplodia theobromae, Rhizoctonia sp, Aspergillus niger, A.tamarii, Penicillium oxalicum, and P.sclerotinum (Calistru and al., 1997; Thangavelu and al., 2004; Okigbo and Okediugwu, 2000; Moreno and Paningbatan, 1995; Mortuza and llag, 1999). The Gloicladium and Trichoderma have been mostly were used as biofungicides agents; they showed a high inhibition against certain fungal diseases, their effects were equal or exceeded at, those which were of some chemical pesticides. (Illipronti and al., 1993; Harman and al., 1980).
The goal of this research was to isolate and to identify the interior associated fungi with three varieties of wheat seeds :( Vitron, Waha, and Cirta. ), and investigate the effect of one antagonistic local isolate of Trichoderma harzianum against the fungal isolates.

\section{MATERIALS AND METHODS}

Wheat seeds: Three samples of local solid wheat seeds (Triticum durum Desf) were brought from Oum-elbouaghi (Algeria) silos yields, follower for varieties: Vitron, Waha, and Cirta. ). They were stored for one year. (Fig.1a).

Isolation and identification of fungal accompanying interior on the seeds: 200 seeds of each variety were sterilized with $10 \%$ sodium hypochlorite solution for 2 min and rinsed twice with sterilized distilled water, the seeds were dried with sterile filter paper and plated (15 seeds per plate), on fresh Potato Dextrose Agar(PDA) medium impregnated with $(10 \%$ of Acetic Acid solution, $1 \mathrm{ml}$ $1100 \mathrm{ml}$ of medium), each replicate has three plates, and incubated for $7-10$ days at $27^{\circ} \mathrm{C}$. The resulting of borne fungus colonies on seeds were sub-cultured by transferring a small mycelia plugs from the colony margins. Pure culture was obtained by sub-culturing three times (Booth, 1977). The fungi were identified on the basis of their morphological and reproductive characters (Booth, 1977; Booth and al., 1990; Robert and al., 1981).

Fungus material: Four isolates of pathogenic fungi, follower for species: Alternaria alternata1, Alternaria alternata2, (Alternaria infectoria /Lewia infectoria), and Fusarium acuminatum, were isolated from wheat seeds. Another sample of antagonist ( Trichoderma harzianum / Hypocrea lixii ) was isolated from the soil of wheat plant. All samples were identified in Laboratory of Microbiology, University of Oumelbouaghi (Algeria), and verified by Professor Thonart Philippe, Microbial biotechnology, Walloon Center of Biology Industrial, University of Liege, Belgium.

In vitro. Evaluation of the antagonistic capability in vitro of Trichoderma harzianum against the pathogenic Fungi, on PDA medium (direct confrontation):

Dual culture technique: For study the confrontation vis-à-vis between the antagonistic fungus and the other pathogenic fungi, two discs $(8 \mathrm{~mm}$ in the diameter) of one week old culture on (PDA), one carrying the stock of the antagonistic agent

(Trichoderma harzianum) and the other of the pathogenic agent were then placed at the periphery of Petri plate $(9 \mathrm{~cm}$ in diameter) at the same distance 
on PDA medium. One disc of each pathogenic agent was maintained as control (alone culture). Each replicates has three plates. Both the dual and alone cultures were incubated at $25^{\circ} \mathrm{C}$ for four days, and measurement of radial mycelia of the fungus was taken every 24 hours. The percentage inhibition of growth (I) was calculated using the formula given below: $[1 \quad \%)=(1-T / C) \times 100]$. Where: I=Percentage inhibition of pathogen growth by antagonists. $\mathrm{C}=$ Radial growth in control. $\mathrm{T}=$ Radial growth in the treatment. The speed of the fungal colony growth (V) was measured using the formula given below (Rapilly, 1968): $V=[($ L2-L1) $+($ L3-L2) $\ldots($ Ln-Ln-1] $/ \mathrm{n}-1, \mathrm{~V}=$ the speed of growth (mm / day), $L=$ mycelia growth $(\mathrm{mm}), \mathrm{L} 1=$ growth in the first day. $\mathrm{Ln}=$ growth in the last day. $D=(D 1+D 2) / 2 . L=D-d / 2 . L=$ the growth of the fungal mycelia $(\mathrm{mm}), \mathrm{D}=$ diameter of the fungal colony $(\mathrm{mm}), \mathrm{d}=$ diameter of the initial fungal disk (Azza and Allam, 2004; Camporota, 1985; Carl and al., 2005; Rapilly, 1968).

Effect of the volatile substances of Trichoderma harzianum on the growth of the pathogenic fungi on the PDA medium (remote confrontation): This method consists in mending the antagonist fungus and the pathogenic one, in two plates separated thereafter, an assembly is carried out by the superposition of two plates, antagonist in bottom and the pathogenic one in top, the junction between the two plates is ensured by layers of parafilm in order to avoid all loss of volatile substances. for study the effect of the volatile substances of Trichoderma harzianum on the growth of the pathogenic fungi on PDA medium, two discs (8mm in the diameter) of one week old culture on (PDA), one carrying the stock of the antagonistic agent ( Trichoderma harzianum) and the other the pathogenic agent, were then placed at the center of Petri plates $(9 \mathrm{~cm}$ in diameter) containing PDA medium. The lids are removed aseptiquement, then the bottom of each plate containing the antagonist tested is placed below that containing the pathogenic fungus, the two juxtaposed bottoms are closed by layers of Parafilm. For the control, a bottom of plate containing the medium alone is invested below a bottom plate containing the pathogenic fungus. Each replicates has three plates, figure (2). Both the dual and the alone cultures were incubated at $25^{\circ} \mathrm{C}$, in the darkness for four days, and measurement of radial mycelia growth were taken every 24 hours. The percentage growth inhibition (I) was calculated like previously (Camporota, 1985; Fadwa and al., 2009). (fig.1c).

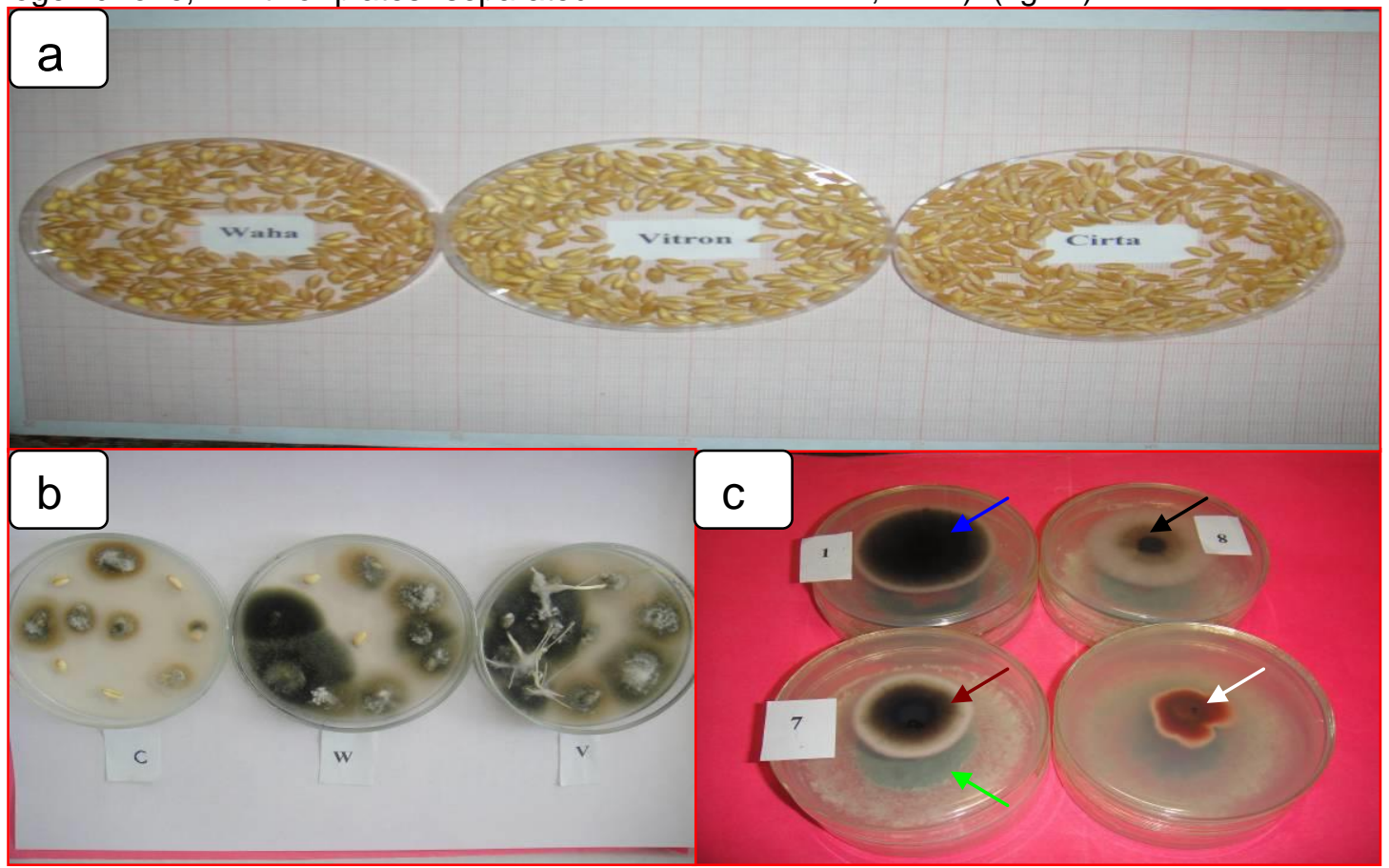

Figure 1: Wheat seeds and isolated fungus used in present study: a: Varieties of wheat seeds used in this study. b:

Some Petri plates with borne fungus on wheat seeds $\mathbf{C}=\mathbf{C i r t a}, \mathbf{W}=$ Waha, V=Vitron. C: Method used in the impact study of the volatile substances of Trichoderma harzianum (green arrows), against the isolated fungus. $1=$ Alternaria alternata1(blue arrow). (7)= Alternaria alternata2 (brown arrow). (8)=Alternaria infectoria (black arrow). Fusarium acuminatum (white arrow). 
RESULTS:

Isolation and identification of fungi accompanying interior in the seeds: The results of isolation on potato-dextrose-agar (PDA) medium and identification of fungal accompanying interior in the seeds clarified about (83) fungus isolates following for species next : Fusarium acuminatum (1 isolate) in a ratio of (1.2\%), and Alternaria(82 isolates) with a ratio of (98.795 \%).The Alternaria isolates apportioned among two species: Alternaria alternata with 39 isolates(12 isolates for: Alternaria alternata1 and 27 isolates for : Alternaria alternata2) and Alternaria infectoria with 43 isolates).And, besides it was clearly seen that the Cirta variety was a lowest infected with fungi(19 isolates) in ratio of $(22.89 \%)$, and both varieties Waha and Vitron with(32 isolates) in a ration equal $(38.554 \%)$ for each one [Figures (1b)and(2)],(Table 1).

Table 1: Isolated fungus from wheat seeds.

\begin{tabular}{|c|c|c|c|c|c|}
\hline & \multicolumn{4}{|c|}{ Fungus species } & \\
\hline Seeds varieties & $\begin{array}{l}\text { Alternaria } \\
\text { alternata1 }\end{array}$ & $\begin{array}{l}\text { Alternaria } \\
\text { alternata2 }\end{array}$ & $\begin{array}{l}\text { Alternaria } \\
\text { infectoria }\end{array}$ & $\begin{array}{c}\text { Fusarium } \\
\text { acuminatum }\end{array}$ & $\begin{array}{c}\text { Total number of } \\
\text { isolates }\end{array}$ \\
\hline Cirta & 6 & 7 & 6 & 0 & 19 \\
\hline Waha & 0 & 9 & 22 & 1 & 32 \\
\hline Vitron & 6 & 11 & 15 & 0 & 32 \\
\hline $\begin{array}{l}\text { Total number of } \\
\text { isolates }\end{array}$ & 12 & 27 & 43 & 1 & 83 \\
\hline
\end{tabular}

figure 2:Isolated fungus from Wheat seeds,

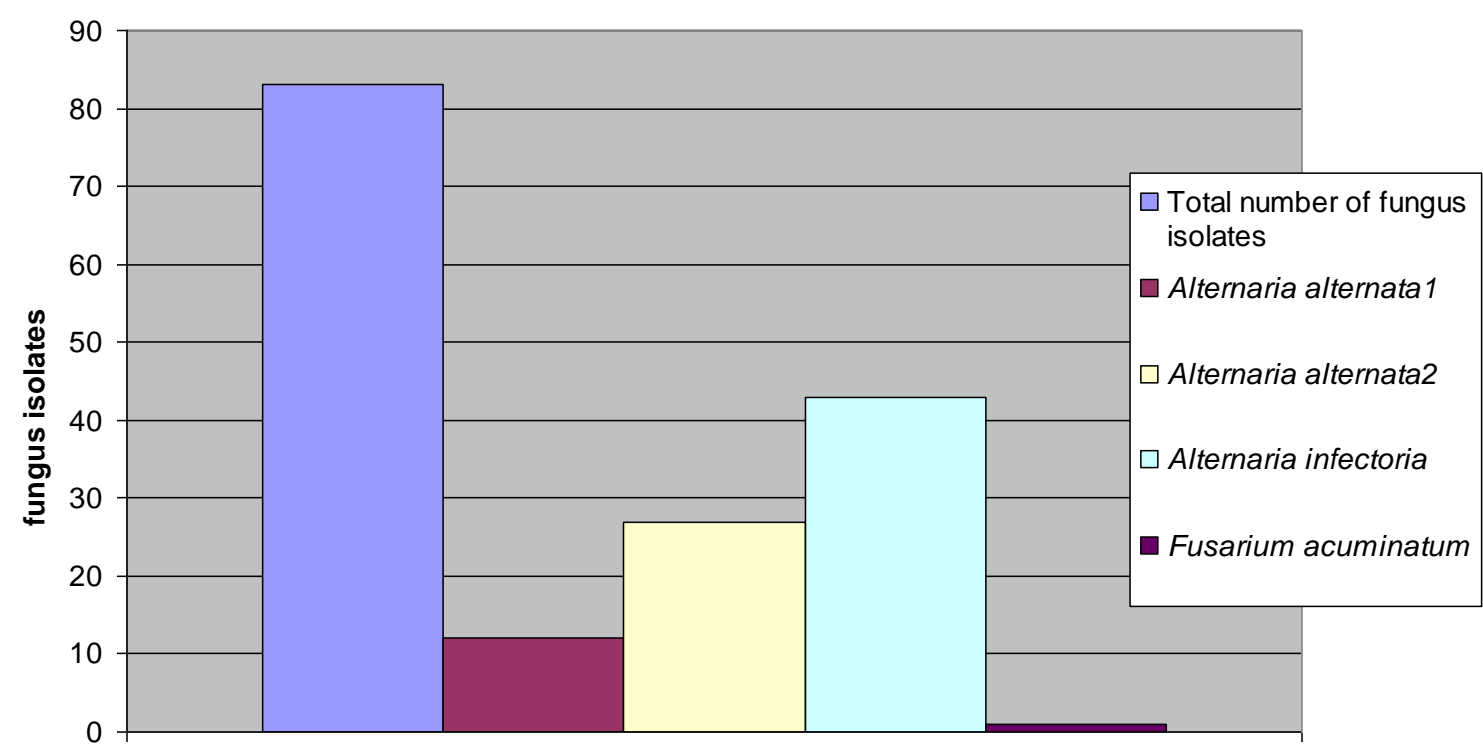

Fungus species 
The antagonistic capability in vitro of Trichoderma harzianum against the pathogenic fungus: The results showed that: 1- The direct confrontation of Trichoderma harzianum against the different fungal isolates in vitro on PDA medium, showed that when the mycelium of both the cultures came in contact with each other the hyphal growth of the pathogenic fungus were found to be inhibited by the hyphae of Trichoderma harzianum. This inhibition with different ratios, it was equal in the fourth day of the experiment to $23 \%, 26.66 \%$ and $40 \%$ for Alternaria alternata1, Alternaria alternata2 and
Alternaria infectoria, respectively, but amounted a lowest ratio in the fourth day to $6.66 \%$ for Fusarium acuminatum .[Table (2) and figures (3), (4-1A),(4$2 A),(4-3 A)$ and $(4-4 A)]$. The present results did not showed any growth of the different Alternaria species when re-planting a disk from the interaction hyphal areas between Trichoderma harzianum and the different Alternaria species from different dual cultures, while Trichoderma harzianum grew[ Figures (4-2B),(4-3B),(4-4B)], except Fusarium acuminatum when grew alone in the plate Figure (4-1B).

Table 2: In vitro. Effect of Trichoderma harzianum mycelia growth in dual cultures, on PDA medium.

\begin{tabular}{|c|c|c|c|c|c|c|}
\hline \multirow{2}{*}{$\begin{array}{l}\text { Test } \\
\text { number }\end{array}$} & \multirow{2}{*}{$\begin{array}{l}\text { Fungus } \\
\text { species }\end{array}$} & \multicolumn{4}{|c|}{$\begin{array}{l}\text { Percentage inhibition } \\
\text { of mycelia growth after: }\end{array}$} & \multirow{2}{*}{$\begin{array}{l}\text { Speed of mycelia } \\
\text { growth in dual } \\
\text { Cultures(cm/day) }\end{array}$} \\
\hline & & 1 day & 2 days & 3 days & 4 days & \\
\hline \multirow[t]{2}{*}{01} & Alternaria alternata1 & l & 00 & 00 & 23 & 1.2 \\
\hline & Trichoderma harzianum & I & l & l & l & 3.6 \\
\hline \multirow[t]{2}{*}{02} & Alternaria alternata2 & 1 & 00 & 00 & 26.66 & 1 \\
\hline & Trichoderma harzianum & I & I & l & l & 4 \\
\hline \multirow[t]{2}{*}{03} & Alternaria infectoria & 1 & 00 & 14.28 & 40 & 0.8 \\
\hline & Trichoderma harzianum & I & I & I & I & 4 \\
\hline \multirow[t]{2}{*}{04} & $\begin{array}{l}\text { Fusarium } \\
\text { acuminatum }\end{array}$ & 1 & 00 & 00 & 6.66 & 1.2 \\
\hline & Trichoderma harzianum & / & l & l & l & 3.4 \\
\hline
\end{tabular}


Agric. Biol. J. N. Am., 2013, 4(2): 145-154

Figure 3 :In vitro, effect of Trichoderma harzianum on the mycelia growth of the pathogenic fungi (dual cultures), on PDA medium.
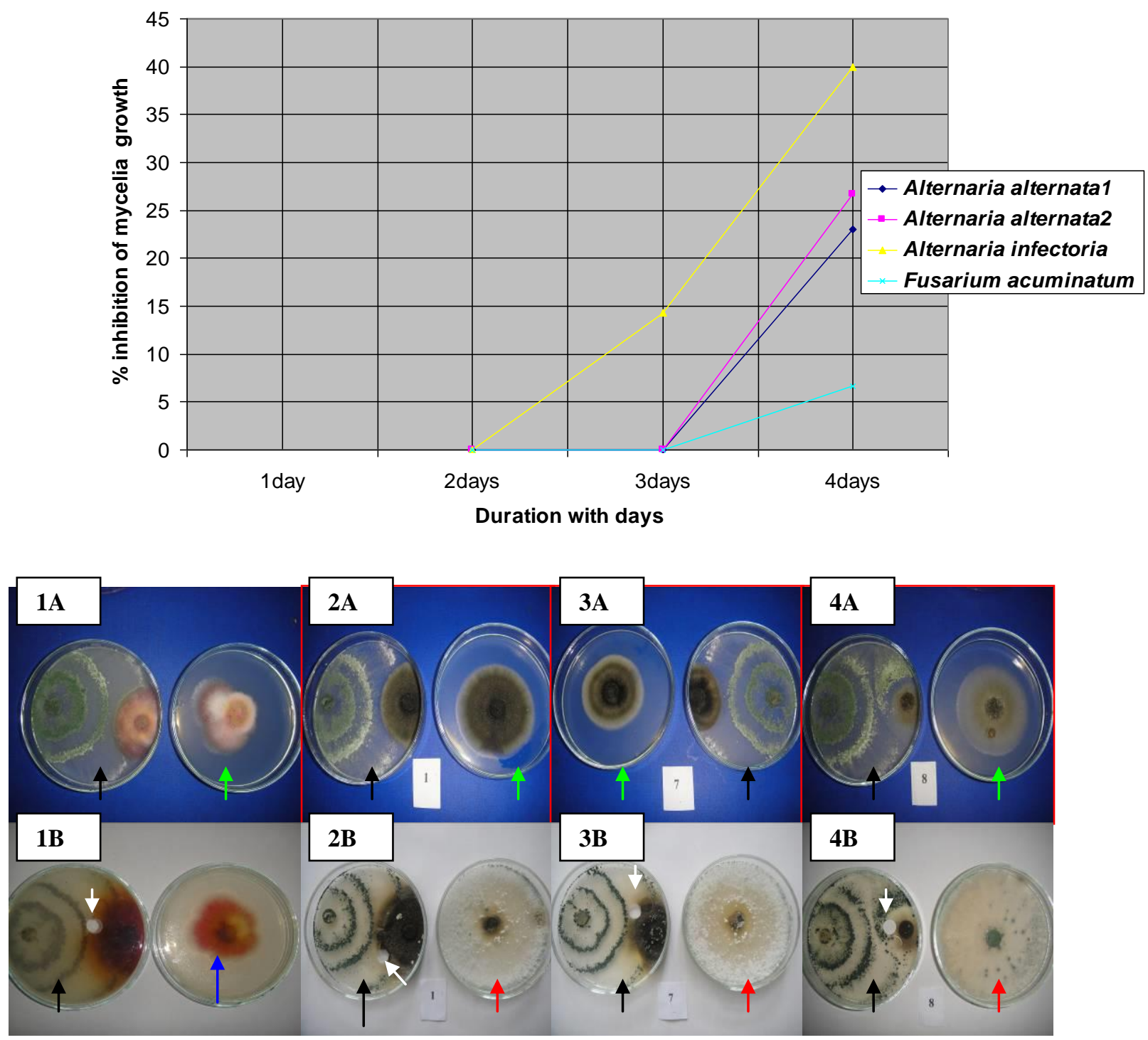

Figure 4: Direct confrontation on PDA medium, between Trichoderma harzianum (green colony), and the different pathogenic fungus, on (dual cultures) (black arrows). Compared with the alone cultures (controls) (green arrows). (1) = Fusarium acuminatum $.(2)=$ Alternaria alternata1. $(3)=$ Alternaria alternata2. $(04)=$ Alternaria infectoria . (A)= First test. (B)=After replanting a disc from the interaction areas (white arrows), where Trichoderma growth only appear (red arrows).or Fusarium acuminatum growth only appear (bleu arrow).

2-The microscopic observations of the different interactions hyphal displayed that the antagonistic fungus affected the pathogenic fungi with decomposition phenomenon (Lyses): the antagonistic fungus was analyzed the mycelia and spores of
Alternaria alternata2 and Alternaria infectoria, figure (5 -3B, 4B), while was analyzed the mycelia of Alternaria alternata1, compared with control. Figure (5-2B). 
Agric. Biol. J. N. Am., 2013, 4(2): 145-154

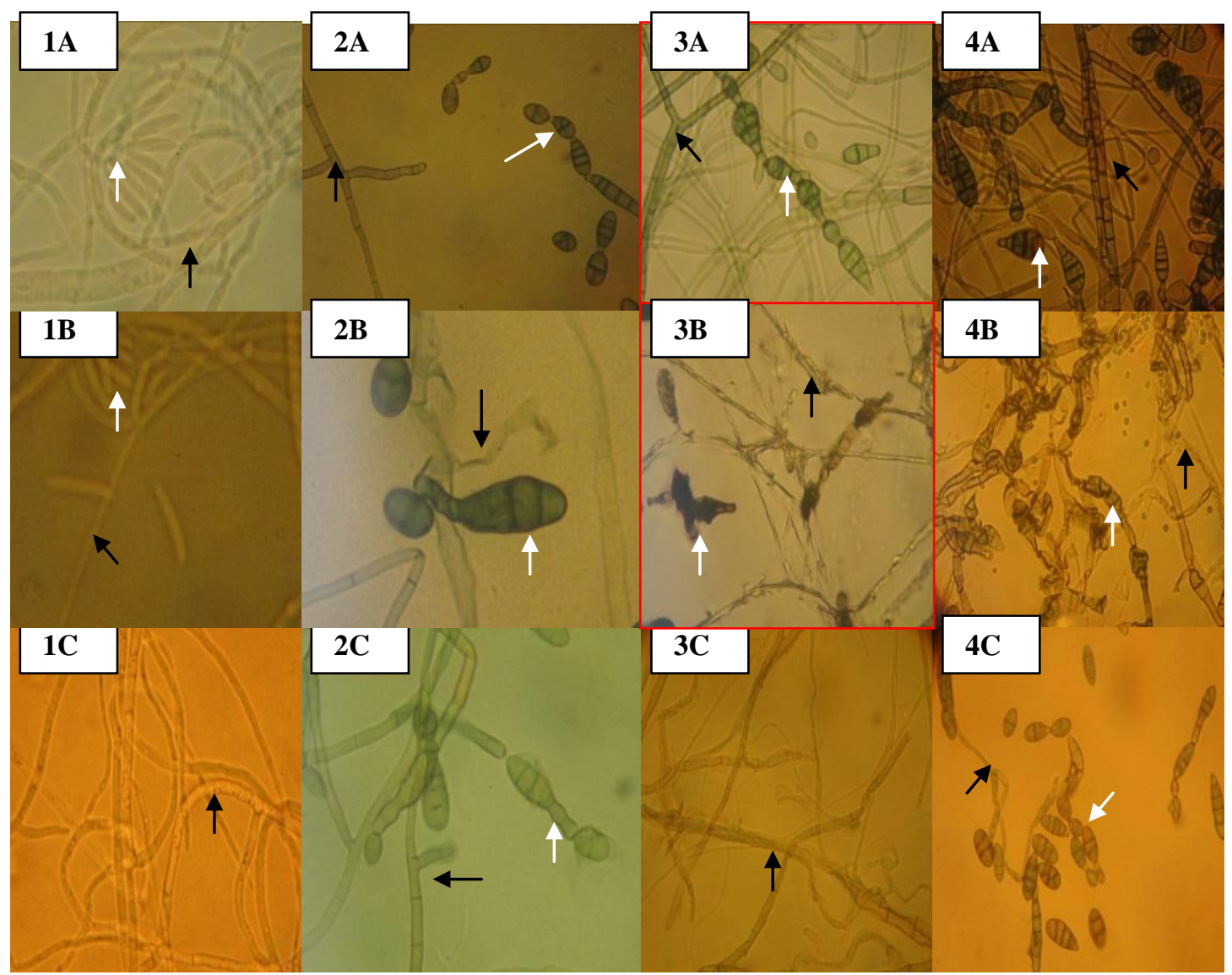

Fig 5: Microscopic observations showed the affect of the Trichoderma harzianum and its volatile metabolite substances on mycelia (black arrows) and on spore formation (white arrows) of the pathogenic fungi compared with controls. (1) = Fusarium acuminatum . (2)= Alternaria alternata1. $(3)=$ Alternaria alternata2. $(4)=$ Alternaria infectoria. $(A)=$ Controls. $(B)=$ Direct confrontation affect. $(C)=$ Volatile substances affect. $40 \times$.

In vitro. Effect of the volatile substances of Trichoderma harzianum on the growth of the pathogenic fungus on PDA medium: The remote confrontation showed that the volatile metabolic substances of the antagonistic fungus inhibited the mycelia growth of the different pathogenic fungus, with different rates over the seven days of treatment, the percentage inhibition of mycelia growth peaked after two days of treatment to reached $12.5 \%$ and $20 \%$ for Alternaria alternata 1 and Alternaria alternata2, respectively, and decreased to $3.22 \%$ in the sixth day in Alternaria alternata 1 and scored in the sixth day a ratio equal to $28 \%$ for Alternaria alternata2, and scored the maximum ratio in the fourth day in Alternaria infectoria to $22.72 \%$, and lowered to $12.9 \%$ in the sixth day, but in the Fusarium acuminatum has recorded the lowest inhibition percentage $20 \%$ in the third day and a highest inhibition percentage $66.66 \%$ in the fourth day. [Table (3) and figure (6)].

The microscopic observations noted that the volatile metabolic substances of Trichoderma harzianum affected on the isolated fungus with the mycelia analysis and prevent the spore's formation of the Alternararia alternata2, (figure, 7-3C), while stopped only the spore formation of Fusarium acuminatum, compared with control. (Figure, 7-1C). 
Table 3: Percentage inhibition of the mycelia growth of isolated fungi by the volatile substances of Trichoderma harzianum, in the dual cultures, on PDA medium.

\begin{tabular}{|c|c|c|c|c|c|c|c|c|}
\hline \multirow{2}{*}{$\begin{array}{l}\text { Fungus } \\
\text { species }\end{array}$} & \multicolumn{2}{l|}{$\begin{array}{l}\text { Percentage inhibition } \\
\text { of mycelia growth after: }\end{array}$} \\
\cline { 2 - 10 } & 1 day & 2 days & 3 days & 4 days & 5 days & 6 days & 7 days & 8 days \\
\hline Alternaria alternata1 & $/$ & 12.5 & 7.14 & 7.69 & 1.96 & 3.22 & $/$ & $/$ \\
\hline Alternaria alternata2 & $/$ & 20 & 20 & 20 & 22.5 & 28 & $/$ & $/$ \\
\hline Alternaria infectoria & $/$ & 0 & 14.28 & 22.72 & 12 & 12.9 & $/$ & $/$ \\
\hline Fusarium acuminatum & $/$ & 0 & 20 & 66.66 & 45 & 43.63 & $/$ & $/$ \\
\hline
\end{tabular}

Figure 6 :The volatile substances effect of Trichoderma harzianum on mycelia growth of isolated fungus.

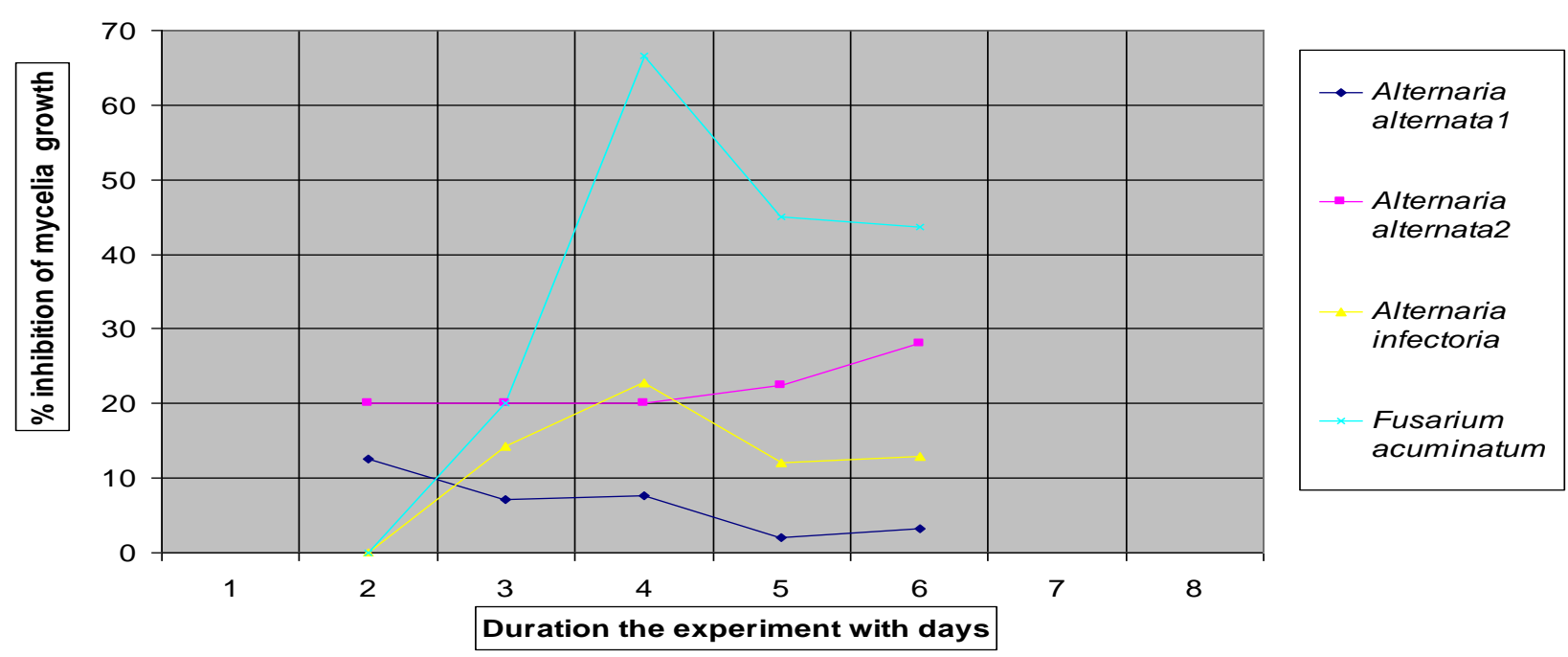

\section{DISCUSSION}

The results of this study revealed that the antagonistic fungus ( Trichoderma harzianum) has a high inhibitory effect against the different isolated fungi, with a several biological modes: 1Competition with his faster growth in the dual cultures compared with those which were of the different isolated fungus (Table 2). 2-lyses (figure 5(2B, 3B, 4B). 3- Volatile substances effect (Table 3) and [Figures $5(1 \mathrm{C}, 3 \mathrm{C})]$. This results has been reported and confirmed by Fadwa and al.(2009) when studying the effect of the antagonism in vitro between six isolates of the antagonistic fungus Trichoderma harzianum and $T$. viride against four pathogenic isolates of Bipolaris and found that the Trichoderma harzianum inhibited the pathogenic 
fungus growth with a different rations, including the following: $68.55-72 \%$ and $69.52-73.32 \%$ for each of B.maydis and B.sorghicola respectively, and 67.02$70.02 \%$ for each of B.sorokiniana and B.tetramra,and Trichoderma viride inhibited the mycelia growth of ( B.maydis and B.sorghicola and B.sorokiniana and B.tetramera ) with ratios as follows: $67.55-74.48 \%$ and $69.52-82.85 \%$ and $68.12-73.61 \%$ and 71.22 $76.66 \%$, respectively, and they inhibited the spore's formation, and found that the volatile metabolic substances of different antagonistic isolates affected the mycelia growth and spores formation of the pathogenic fungus with a different rates, with recording a different degrees of parasitism of various antagonistic fungi at the pathogenic isolates. Hibar and al. (2005) found that the antagonism in vitro of Trichoderma harzianum against Fusarium oxysporium showed an inhibition on the pathogenic fungus growth with a ratio more than $65 \%$, moreover the volatile metabolism substances of the antagonism reduced the pathogenic fungus growth by $63 \%$ compared with controls. Comporota, (1985) studied the antagonism in vitro, between 28 biological isolation of Trichoderma, follower for species: 14 isolates of T.harzianum, 5 isolates of T.hamatum, 3 isolates of T.viride, one of T.koningii and 5 nonspecific type, on 3 isolates of the pathogenic fungus Rhizoctonia solani Kuhn, and the different antagonistic isolates showed a different effect on the pathogenic fungus which affected the mycelia growth with a different degrees, and their volatile metabolism substances inhibited the mycelia growth and spores formation of the pathogenic fungi. And also including by Larralde et al. (2008) when they chose 9 fungal isolates of Trichoderma: 2 of T.atroviride, 2 of T.longibrachiatum and 1 of each T.reesi and T.koningiopsis and T.citrinoviride and 02 did nospecific type from 30 isolates of Trichoderma, where they inhibited the growth of pathogenic fungus( Macrophomina phaseolina) with proportions higher than $50 \%$ during the antagonism study, and the microscopic observations in the hyphal interaction showed that the fungal antagonistic fungus has an ability to analyze the hyphae and sclerotes of the pathogenic fungus, the analysis of the metabolic substances of these antagonistic fungi in laboratory revealed that there is a positive correlation between

\section{ACKNOWLEDGEMENTS}

This study was conducted in the Microbiology Laboratory, Department of Nature and Life Sciences, University of Larbi Ben Mhidi, Oum-elbouaghi, and the strength of inhibition of these fungi with the high quantity of enzymatic production of B-1, 3glucanase and $\mathrm{N}$-acetylhexosaminade .Azza and Allam (2004) discovered that the Trichoderma $s p$ isolates have a strong antagonism against wilt diseases caused by Fusarium $s p$, in vitro , on potato dextrose agar medium, when decreased his growth with the following proportions: $(88 \%),(86 \%)$ and $(80 \%)$ for Trichoderma harzianum, T.hamatum and T. viride respectively. Ramsy (1991) Found that the Rhizopus stolonifer and Trichoderma harzianum and $T$. viride, inhibited the mycelia growth, and lowered the proportion of spore germination and spore tube lengths of Bipolaris oryzae and Pyricularia oryzae .The treatment of cowpea seeds with spore suspension of Trichoderma viride has protected them against the brown blotch disease which was caused by Colletotrichum truncatum and found that the T.viride produced a volatile and non-volatile organic compounds, Viridin and antibiotics, biofungicides( Bankole and Adebanjo, 1996). Also was found that the Trichoderma viride isolate (T60) when used as a commercial biopesticide against Coniophora puteana and Postia placenta and Serpula lacrymans has a multiple effects with a volatile and non-volatile organic compounds, Lytic enzyme and soluble antibiotics in the water, and nutrient competition(Brown and Bruce, 1999; Brown and al., 1999 ). Interactions between Trichoderma harzianum strains and some soil borne plant pathogens (Gaeumannomyces graminis var. tritici, Fusarium culmorum and $F$. moniliforme) were studied on PDA medium. All $T$. harzianum strains tested produced a metabolite that inhibited growth of plant pathogenic fungi on PDA medium. When grown in liquid cultures containing laminarin, chitin or fungal cell walls as sole carbon sources, 2 strains of $T$. harzianum produced 1, 3-b-glucanase and chitinase in the medium, higher levels of these enzymes were induced by $T$. harzianum T15 (Cigdem and Merih, 2004). These results showed that a high efficacy of this local isolate of Trichoderma harzianum, against a few dangerous pathogenic fungi, this study strongly suggests that this Trichoderma harzianum isolate can be exploited for the biological control of seed diseases at the field level.

will be presented as part of the doctoral dissertation of the first author, Hamitou, M. We are grateful to Professor Thonart Philippe, Microbial biotechnology, Walloon Center of Biology Industrial, University of Liege, Belgium, for confirmation the identification of the fungus isolates. 


\section{REFERENCES}

Andersen, B.,Sorensen, J.L.,Nielsen, K.F.,Gerrits, van.den.Ende.B., de hoog,S.(2009) A polyphasic approach to the taxonomy of the Alternaria infectoria species-group. Fungal Genet Biol.46 (9):642-56.

Azza, A.Tawfik. And D.A.Allam. (2004) Improving cumin production under soikl infestation with Fusarium Pathogen 1-screening of biocontrol agents. Ass. Univ. Bull.Environ.Res.2, 35-45.

Bankole, S.A., A.Adebanjo. (1996) Biocontrol of brown blotch of Cowpea caused by Colletotricum truncatum with Trichoderma viride .Crop Prot.15:633-636.

Booth, C. (1977) Fusarium laboratory guide to the identification of the Major species .Common wealth Mycological Institute. England.58p.

Botton, .,Breton, A., Fevre, M.,Gauthir, S., Larpent, J.P., Gay,P.H., Reymond. P., Sanglier, J.J., VayssierY.and Veau, P. (1990) Moisissures utiles et nuisible importance industrielle 2 ème Ed .Masson, Paris. Milan, Barcelone, Mexico, 512pp.

Brown, H.L., A. Bruce. (1999) Assessment of the biocontrol Potentia of aTrichoderma viride isolate Part I: Establishmen of field and fungal cellartials.Int.Biodeterior Biodegard.44:219-223.

Brown, H.L., A.Bruce., H.J.Staines. (1999) Assessment of the Biocontrol Potential of a Trichoderma viride isolate Part II: Protection against soft rot and basidiomycete decay.Int. Biodeterior .Biodegad.44:225-231.

Calistru, C., M.McLean, .P.Berjak. (1997) In vitro studies on the Potential for Biological control of Aspergillus flavus and Fusarium moniliforme by Trichoderma species1. Macro- Scopical and microscopical observations of fungal interactions Mycopathologia.139:115-121.

Camporota, Pierre. (1985) Antagonisme in vitro de Trichoderma spp vis-à-vis de Rhizoctonia solani Kuhn. Agronomie, 5(7):613-620.

Carl, A.Strausbaugh., Ken, Overturf., and Anita, C.Koehn. (2005) Pathogenicity and real-time PCR detection of Fusarium spp.in wheat and barley roots. Can.J.Plant Pathol.27:430-438.

Cigdem, Kucuk., Merih, Kivanc. (2004) In Vitro Antifungal Activity of Strains of Trichoderma harzianum. Türk. J Biol.28:111-115.

Fadwa.Beber, Amina, Ouazzani, Touhami., Alain, Badoc., Allal, Douira. (2009)

Antagonisme in vitro ET in vivo de deux Trichoderma à l'Egard de quatre espèces de Bipolaris pathogens sur le Sorgho. Bull, Soc.Pharm, Bordeaux, 148:93-114.

Fernandez, A., Stroshine, A. and Tuit, J. (1984) Mold growth and carbon dioxide Production during storagee of high Moisture corn Cereal Chemistry,62:137-144.

Harman, G.E., I.Chet and Baker. (1980) Trichoderma harzianum Effects on seed and seedling disease induced in radish and pea By Pythium spp or Rhizoctonia solani. Phytopathology.70:1167-1172.

Hibar, Khaled., Mejda, DaamiRemadi., Haifa, Khiareddine., Mohamed Elmahjoub. (2005) Effet inhibiteur in vitro et in vivo du Trichoderma harzianum sur Fusarium oxysporium f.sp.radicislycopersici. Biotechnol.Agron. Soc.Environ.9 (5):163-171.

Illipronti, R.A., Jr.Marchado, J.Dac. (1993) Antagonism of fungi to Sclerotinia sclerotiorum in soybean and common bean. Fitopatologia Brasileira. 18:162-166.

Jegathambigai, V., R. S. Wilson. Wijeratnam and R.L.C. Wijesundera. (2009) Trichoderma as a seed treatment to control Helminthosp- orium leaf spot disease of Chrysalidocarpus lutescens.World Journal of Agricultural Sciences.5 (6):720-728.

Larrade-Corona, C.P., M.R.Santiago-Mena., A.M.Sifuente Rincon., I.C.Rodriguez Perez., K.Shirai., J.A.Narvaez Zapata. (2008) Biocontrol potential characterization of novel native Trichoderma strains against Macrophomina phaseolina isolated from sorghum and common bean. Appl. Microbiol Biotechnol: 167-177.

Mausam, Verma., Satinder. K.Brar., R.Y.Surampalli., J.R.Valero. (2007) Antagonistic Fungi, Trichoderma spp. Panoply of Biological control. Biochemical Engineering Journal, 37:1-20.

Moreno, M.E. and G.Vidal-Gaona. (1986) Preserving the viability of Seed with fungicides. Plant Disease, 65:260-261.

Moreno, L.S., R.A.Paningbatan. (1995) Biological control of mango Stem-end rot caused by Diplodia natalensis with Trichoderma Viride. Philippine Phytopathol.31:103-116.

Mortuza, H.G., L.L.llag. (1999) Potential for biocontrol of Lasiodiplodimaea theobro (Pat) Griff.and Maubl.in banana fruits by Trichoderma species. Biol. Control.15:235-240.

Okigbo, R.N., F.E.Oikediugwu. (2000) Studies on biological control of post harvest rot in yams Dioscorea spp using Trichoderma viride. J.Phytopathol.148:259-263.

Ramsy, M.R. (1991) Studies on rice diseases in Egypt Ph.D.Thesis, Faculty of Agric. Alexandria Universit

Rapilly, F. (1968) Les techniques de mycology en pathologie Végétale. Annales Epiphyties, INRA. Paris, $210 p$.

Rémi, Champion. (1997) Identifier les champignons transmis par les semences.INRA. France, 399p.

Robert, A. Samson, Ellen, S. Hoekstra. And Connie, A.N.Vanoorschot. (1981) Introduction to -Food-borne Fungi C.B.S, Institute of the Royal Netherlands.Academy Arts and Sciens.

Thangavelu, R., A.Palaniswami., R.Velazhahan. (2004) Mass production of Trichoderma harzianum for managing fusarium wilt of banana. Agri. Ecosys. Environ.103:259-263 